\title{
EFFECT OF THE CNT GROWTH TEMPERATURE ON THE TENSILE STRENGTH OF CARBON FIBER
}

\author{
KAZUTO TANAKA, YOSHITAKA HINOUE, YUKI OKUMURA \& TSUTAO KATAYAMA \\ Department of biomedical Engineering, Doshisha University, Japan
}

\begin{abstract}
Carbon fiber reinforced plastics (CFRPs) are expected to be used for the structural parts of automobiles and aircrafts due to their mechanical properties, including high specific stiffness and high specific strength. It was reported that grafting of carbon nanotubes (CNTs) on the carbon fiber can improve the fiber matrix interfacial property, which plays an important role in the mechanical behavior of CFRP. On the other hand, grafting CNTs using the chemical vapor deposition (CVD) method sometimes weakens the tensile strengths of carbon fibers. In particular, when the growth temperature is relatively high, the fiber degradation is remarkable. In this study, CNTs were grafted on carbon fibers at growth temperatures from 550 to $700^{\circ} \mathrm{C}$ using $\mathrm{Ni}$ as the catalyst, and their tensile strengths were measured by single fiber tensile tests. The results indicated that the CVD processes, especially the higher temperature heat-treatment, accelerate the diffusion of catalysts into carbon fibers, and degrade the fiber strength. When the growth temperature was relatively low $\left(550-600^{\circ} \mathrm{C}\right)$, there was no degradation of tensile strength for CNT grafted carbon fibers.
\end{abstract}

Keywords: CFRP, Carbon Nanotube (CNT), Chemical Vapor Deposition (CVD), CNT grafted carbon fiber, single fiber tensile test, tensile strength

\section{INTRODUCTION}

In recent year, Carbon fiber reinforced plastics (CFRPs) are expected to be used for the structural parts of automobiles and aircrafts due to their mechanical properties including high stiffness, high strength and low density. The mechanical behavior of composites depends not only on the properties of the reinforcing fibers, but also on the characteristics of the interface between the fiber and matrix. The fiber matrix interface is responsible for stress transfer from the matrix to the carbon fibers. It was reported that grafting of carbon nanotubes (CNTs) on the carbon fiber can improve the fiber matrix interfacial shear strength (IFSS) due to the increase of the surface area and mechanical interlocking by CNTs [1], [2].

CNTs are graphene sheets in the shape of a tube whose diameter is on the nanometer order. With their small size and remarkable mechanical, electrical and thermal properties, CNTs have been considered as promising materials to use in advanced composites [3]. Most CNTs are produced by carbon-arc discharge, laser ablation, and chemical vapor deposition (CVD). Of these, CVD provides a typical method to graft CNTs directly onto carbon fibers [3]-[5]. On the other hand, grafting CNTs using the CVD method sometimes weakens the strength of carbon fibers. In the previous studies, CNTs were grafted onto carbon fiber at over $700^{\circ} \mathrm{C}$ and the tensile strength of CNT grafted carbon fiber was decreased [2], [6], [7].

In this paper, we focused on the effect of growth temperature on fiber degradation. CNTs were grafted on carbon fibers at growth temperatures from $550^{\circ} \mathrm{C}$ to $700^{\circ} \mathrm{C}$ using $\mathrm{Ni}$ as the catalyst and ethanol as the carbon source. The tensile strength of Ni plated and CNT grafted carbon fibers were measured by single fiber tensile tests. 


\section{MATERIALS AND EXPERIMENTAL PROCEDURES}

\subsection{Materials}

Spread PAN-based carbon fibers for 24K (Nippon Tokushu Fabric) were used in this study. $\mathrm{Ni}$ was carried onto the surface of carbon fibers by electrolytic Ni plating method. The components of plating bath were Nickel sulfate hexahydrate $(240 \mathrm{~g} / \mathrm{L})$, Nickel chloride hexahydrate $(45 \mathrm{~g} / \mathrm{L})$ and Boracic acid $(30 \mathrm{~g} / \mathrm{L})$. The fiber bundles were connected on one end side to the electrode and dipped in the plating bath. The plating time is set for $15 \mathrm{~s}$ and the current density is set for $0.13 \mathrm{~mA} / \mathrm{mm}^{2}$. The morphology of the surface of carbon fibers was examined by scanning electron microscope (SEM, JSM-6390LT, JEOL) and field emission scanning electron microscope (FE-SEM, JSM-7500FD, JEOL). To evaluate the effect of the heat treatment on the reaction of $\mathrm{Ni}$ to carbon fibers, Ni plated carbon fibers were heat-treated at $600^{\circ} \mathrm{C}$ and $700^{\circ} \mathrm{C}$ for $30 \mathrm{~min}$. Before and after the heat treatment, the size of Ni particles in $1 \mu \mathrm{m}^{2}$ was measured by SEM.

\subsection{Growth of CNTs on carbon fibers}

CNTs were directly grafted onto carbon fibers by CVD system (MPCVD-70, Microphase) at $550^{\circ} \mathrm{C}, 600^{\circ} \mathrm{C}, 650^{\circ} \mathrm{C}$ and $700^{\circ} \mathrm{C}$ with a flow of ethanol at a flow rate of $2 \mathrm{~mL} / \mathrm{min}$ as the carbon source to grow CNTs. The spread carbon fiber bundles on a ceramic tray were placed into a quartz tube. After purging with Ar gas at the flow rate of $200 \mathrm{~mL} / \mathrm{min}$, the temperature of quartz tube was raised to the growth temperature and ethanol gas was injected for 30 mins. After exposure to ethanol gases, the tube and carbon fibers were cooled down to room temperature under flowing Ar.

\subsection{Single fiber tensile test}

The tensile strengths of as-received carbon fiber, heat-treated carbon fibers, heat-treated $\mathrm{Ni}$ plated carbon fibers and CNT grafted carbon fibers were measured by single fiber tensile test. A single filament was separated from the spread fiber bundles and attached to the film with a gauge length of $15 \mathrm{~mm}$, as show in Fig. 1. Single fiber tensile tests were conducted by micro-material testing machine (MMT, MMT-11N, Shimadzu) with a $2.5 \mathrm{~N}$ load cell and displaced at an extension rate of $1.67 \times 10^{-5} \mathrm{~m} / \mathrm{s}(1 \mathrm{~mm} / \mathrm{min})$. The diameter of the carbon fiber was measured by SEM after each tensile test. Ten single fibers were tested for each condition.

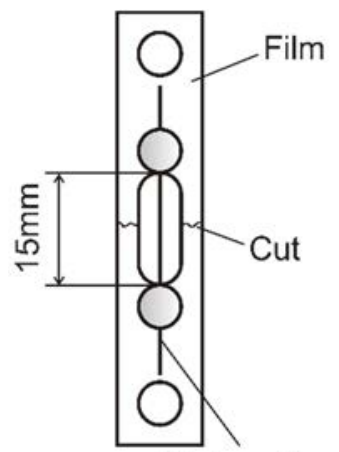

Carbon fiber

Figure 1: Schematic drawing of tensile test specimen. 


\section{RESULTS AND DISCUSSIONS}

\subsection{Effect of heat-treatment on Ni particles}

Fig. 2 shows the surface of Ni plated carbon fiber. Ni exists on the carbon fiber surface in a state of particle. Ni plated carbon fibers heat-treated at $600^{\circ} \mathrm{C}$ and $700^{\circ} \mathrm{C}$ are shown in Fig. 3 and measured Ni particle size is shown in Fig. 4. While Ni particles size of heattreated $\mathrm{Ni}$ plated carbon fibers at $600^{\circ} \mathrm{C}$ is same as that of untreated one, that at $700^{\circ} \mathrm{C}$ has smaller Ni particle size. This indicates that the diffusing of Ni particles into carbon fibers occurred over $600^{\circ} \mathrm{C}$.

\subsection{Results of single fiber tensile strength}

Fig. 5 shows $\mathrm{CNT}$ grafted carbon fibers at growth temperature of $550^{\circ} \mathrm{C}, 600^{\circ} \mathrm{C}, 650^{\circ} \mathrm{C}$ and $700^{\circ} \mathrm{C}$. While the carbon fiber at growth temperature of $550^{\circ} \mathrm{C}$ was coated with short CNTs, longer CNTs, about micro-meter order, are grafted on the carbon fibers over $600^{\circ} \mathrm{C}$ for growth temperature.

The results of single fiber tensile tests for heat-treated carbon fibers, heat-treated $\mathrm{Ni}$ plated carbon fibers and CNT grafted carbon fibers are respectively represented in Figs. 6, 7 and 8. Carbon fibers without Ni catalyst did not show any decrease in tensile strength under all conditions. On the other hand, the degradation of the tensile strength can be seen for the $650^{\circ} \mathrm{C}$ and $700^{\circ} \mathrm{C}$ conditions in both Figs 7 and 8 . At $650{ }^{\circ} \mathrm{C}$, the tensile strength of Ni plated fiber and CNT grafted fiber showed 4.0 GPa and $4.6 \mathrm{GPa}$, decreases of $21 \%$ and $10 \%$ as compared to as-received fiber $(5.1 \mathrm{MPa})$, respectively. At $700^{\circ} \mathrm{C}$, the tensile strength of Ni plated fiber and CNT grafted fiber were $48 \%$ and $45 \%$ lower than that of as-received fiber. As shown in Fig. 4, the diffusion of Ni particles into carbon fibers is indicated to occur over $600^{\circ} \mathrm{C}$ for heat-treatment. This significant degradation of tensile strength is considered to come from the diffusing of $\mathrm{Ni}$ into carbon fiber. The strength of CNT grafted carbon fibers is strongly influenced by the interaction of Ni particle with the carbon fiber.

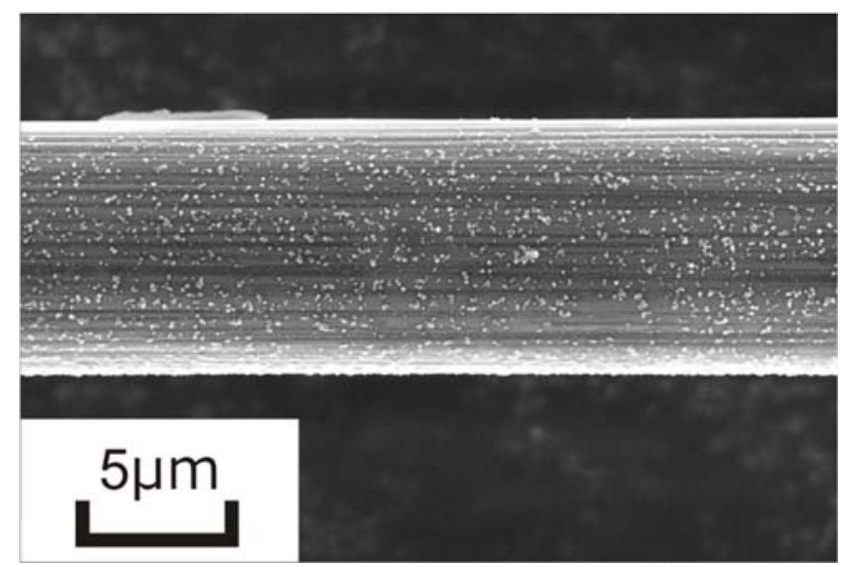

Figure 2: SEM images of the Ni plated carbon fiber. 


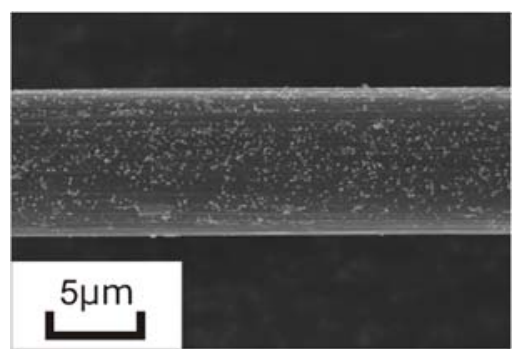

(a) $600^{\circ} \mathrm{C}$

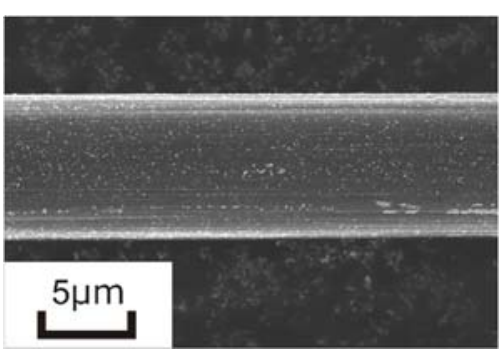

(b) $700^{\circ} \mathrm{C}$

Figure 3: SEM images of Ni plated carbon fibers heat-treated at $600^{\circ} \mathrm{C}$ and $700^{\circ} \mathrm{C}$.

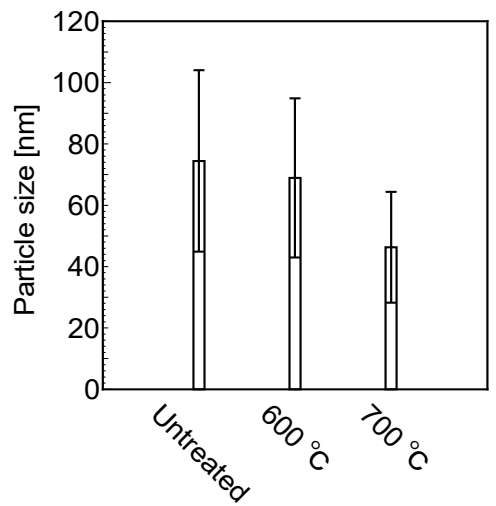

Figure 4: Ni particle size on the surface of carbon fibers heat-treated at $600^{\circ} \mathrm{C}$ and $700^{\circ} \mathrm{C}$.

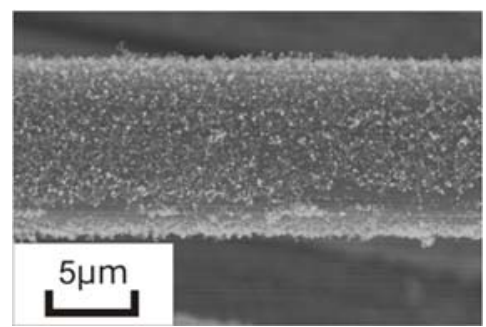

(a) $550^{\circ} \mathrm{C}$

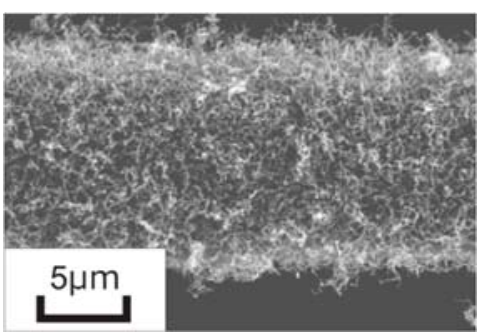

(c) $650^{\circ} \mathrm{C}$

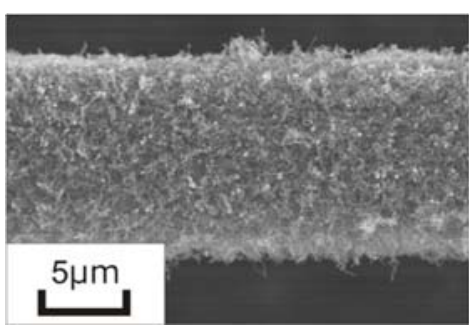

(b) $600^{\circ} \mathrm{C}$

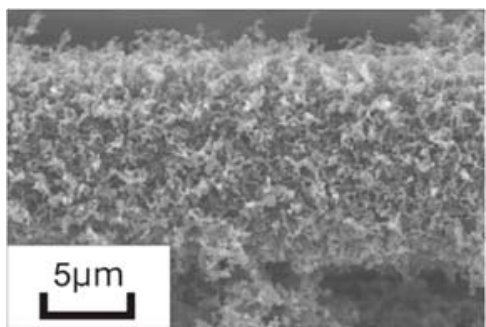

(d) $700^{\circ} \mathrm{C}$

Figure 5: $\mathrm{CNT}$ grafted carbon fibers at growth temperature of $550^{\circ} \mathrm{C}, 600^{\circ} \mathrm{C}, 650^{\circ} \mathrm{C}$ and $700^{\circ} \mathrm{C}$. 


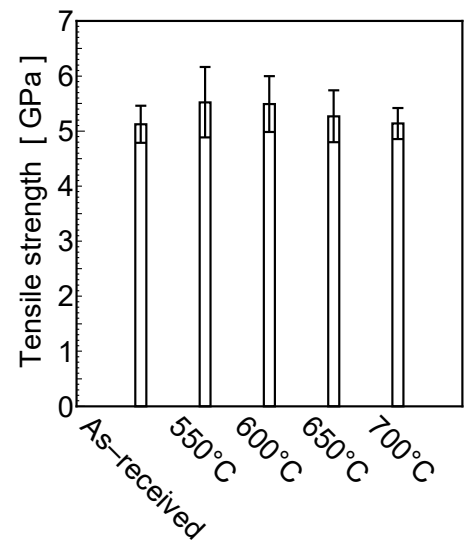

Figure 6: Tensile strengths of heat-treated carbon fibers at different temperatures.

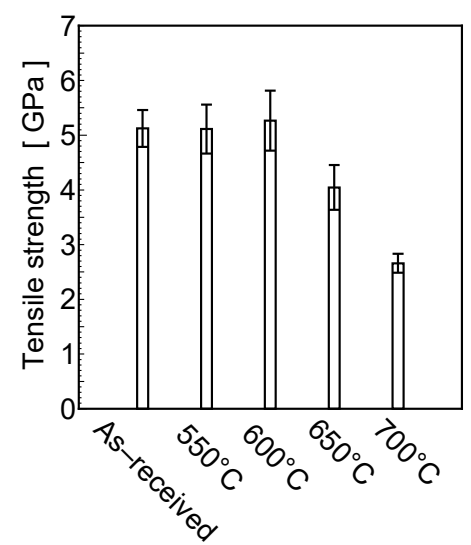

Figure 7: Tensile strengths of Ni plated carbon fibers heat-treated at different temperatures.

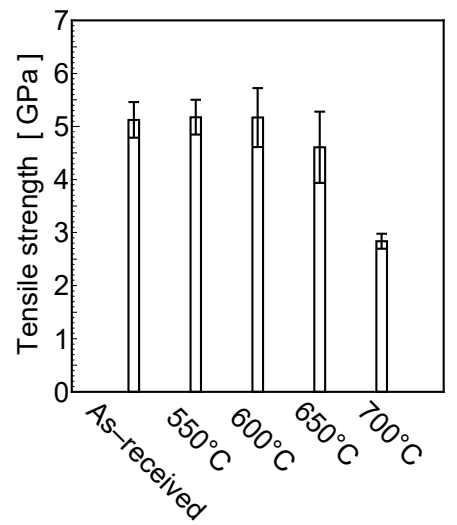

Figure 8: Tensile strengths of CNT grafted carbon fibers produced with the CVD process at different growth temperatures. 
Weibull plots of tensile strength for Ni plated carbon fibers and CNT grafted carbon fibers are shown in Figs. 9 and 10. Several studies reported that the growth of CNTs on carbon fiber improves the tensile strength of carbon fiber as a result of increasing of crosslinks between carbon crystals and repairing the damages of fiber surface by the growth of CNTs [7], [8]. At $650^{\circ} \mathrm{C}$, some of damages caused by diffusing of Ni particles are considered to be repaired by growth of CNT.

\section{CONCLUSIONS}

CNTs were grafted on carbon fibers at growth temperatures from $550^{\circ} \mathrm{C}$ to $700^{\circ} \mathrm{C}$ using $\mathrm{Ni}$ as the catalyst and ethanol as the carbon source. The tensile strength of Ni plated and CNT grafted carbon fibers were measured by single fiber tensile tests. The investigation yielded the following conclusions:

The size of $\mathrm{Ni}$ particles on the surface of carbon fibers was decreased by the heat treatment at $700^{\circ} \mathrm{C}$. This indicated that the heat-treatment accelerates the diffusion of $\mathrm{Ni}$ particles into carbon fibers.

There was no degradation of tensile strength for CNT grafted carbon fibers at the temperature of $550^{\circ} \mathrm{C}$ and $600^{\circ} \mathrm{C}$. The tensile strength of Ni plated and CNT grafted carbon fibers heat-treated at over $650^{\circ} \mathrm{C}$ was decreased by the fiber degradation due to the diffusion of catalysts into fibers.

\section{ACKNOWLEDGEMENTS}

This work was partially supported by KAKENHI (Japan Society for the Promotion of Science, Grant-in-Aid for Scientific Research (B)) (26289011) and a research project on "Research and Development Center for Advanced Composite Materials" of Doshisha University and MEXT (the Ministry of Education, Culture, Sports, Science and Technology, Japan) - Supported Program for the Strategic Research Foundation at Private Universities, 2013-2017, the project S1311036.

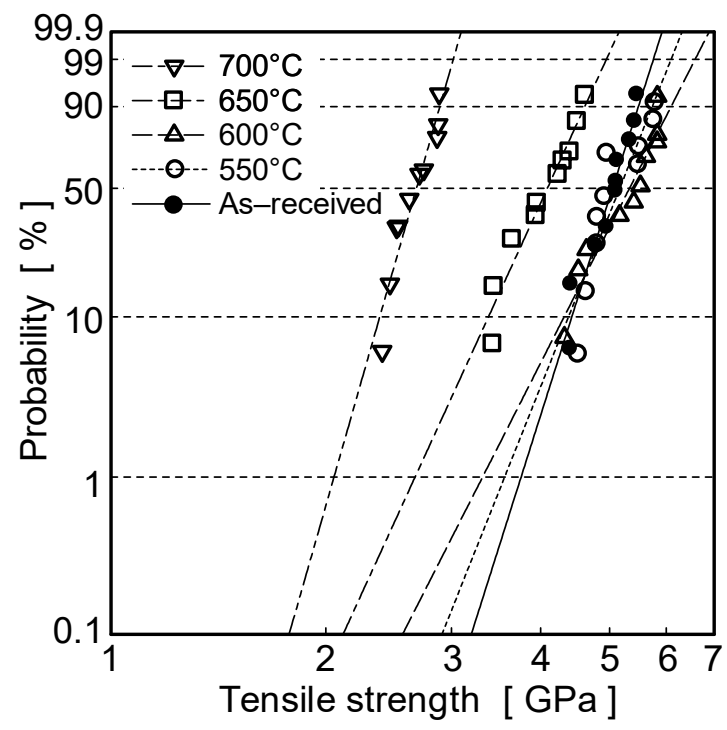

Figure 9: Weibull plots for as-received carbon fibers and Ni plated carbon fibers heattreated at different temperatures. 


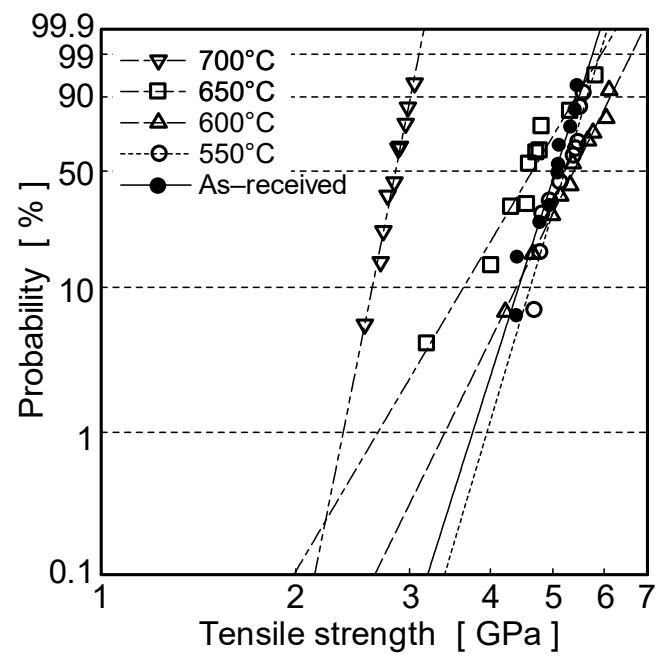

Figure 10: Weibull plots for as-received carbon fibers and CNT grafted carbon fibers produced with the CVD process at different growth temperatures.

\section{REFERENCES}

[1] Tanaka, K., Okumura, Y., Katayama, T. \& Morita, Y., Effect of Carbon Nanotubes Deposition Form on Carbon Fiber and Polyamide Resin Interfacial Strength. Journal of the Society of Materials Science, 65(8), pp. 586-591, 2016.

[2] Qian, H., Bismarck, A., Greenhalgh, E.S., Kalinka, G. \& Shaffer, M.S.P., Hierarchical Composites Reinforced with Carbon Nanotube Grafted Fibers: The Potential Assessed at the Single Fiber Level. Chemistry of Materials, 20(5), pp. 1862-1869, 2008.

[3] Thostenson, E.T., Li, W.Z., Wang, D.Z., Ren, Z.F. \& Chou, T.W., Carbon nanotube/carbon fiber hybrid multiscale composites. Journal of Applied Physics, 91, pp. 6034-6037, 2002.

[4] Li, W.Z., Wang, D.Z., Yang, S.X., Wen, J.G. \& Ren, Z.F., Controlled growth of carbon nanotubes on graphite foil by chemical vapor deposition. Chemical Physics Letters, 335(3-4), pp. 141-149, 2001.

[5] Zhu, S., Su C.H., Lehoczky, S.L., Muntele, I. \& Ila, D., Carbon nanotube growth on carbon fibers. Diamond and Related Materials, 12(10), pp. 1825-1828, 2003.

[6] Lv, P., Feng, Y.Y., Zhang, P., Chen, H.M., Zhao, N. \& Feng, W., Increasing the interfacial strength in carbon fiber/epoxy composites by controlling the orientation and length of carbon nanotubes grown on the fibers. Carbon, 49(14), pp. 4665-4673, 2011.

[7] Zhang, Q., Liu, J., Sager, R., Dai, L. \& Baur, J., Hierarchical composites of carbon nanotubes on carbon fiber: Influence of growth condition on fiber tensile properties. Composites Science and Technology, 69(5), pp. 594-601, 2009.

[8] Kim, K.J., Kim, J., Yu, W.R., Youk, J.H. \& Lee, J., Improved tensile strength of carbon fiber undergoing catalytic growth of carbon nanotubes on their surface. Carbon, 54, pp. 258-267, 2013.

[9] Naito, K., Tanaka, Y., Yang, J.M. \& Kagawa, Y., Tensile properties of carbon nanotubes grown on carbon fibers. The 18rd Material Processing Technical Conference, 2010. 